\title{
Hepatic phosphorylation status of serine/threonine kinase 1, mammalian target of rapamycin signaling proteins, and growth rate in Holstein heifer calves in response to maternal supply of methionine
}

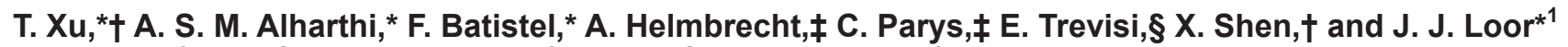 \\ *Department of Animal Sciences and Division of Nutritional Sciences, University of Illinois, Urbana 61801 \\ †College of Veterinary Medicine, Nanjing Agricultural University, 210095 Nanjing, PR China \\ ‡Evonik Nutrition \& Care GmbH, 63457 Hanau-Wolfgang, Germany \\ §Institute of Zootechnics, Faculty of Agriculture, Food and Environmental Science, Università Cattolica del Sacro Cuore, Piacenza 29122, Italy
}

\begin{abstract}
The study investigated whether methionine supply during late pregnancy is associated with liver mammalian target of rapamycin (MTOR) pathway phosphorylation, plasma biomarkers, and growth in heifer calves born to cows fed a control diet $(\mathrm{CON})$ or the control diet plus ethylcellulose rumen-protected methionine (MET; $0.09 \%$ of dry matter intake) for the last $28 \mathrm{~d}$ prepartum. Calves were fed and managed similarly during the first $56 \mathrm{~d}$ of age. Plasma was harvested at birth and 2, 7, 21, 42, and $50 \mathrm{~d}$ of age and was used for biomarker profiling. Liver biopsies were harvested at $4,14,28$, and $50 \mathrm{~d}$ of age and used for protein expression. Body weight, hip height, hip width, wither height, body length, rectal temperature, fecal score, and respiratory score were measured weekly. Starter intake was measured daily, and average daily gain was calculated during the first 8 wk of age. During the first 7 wk of age, compared with calves in the CON group, calves in the MET group had greater body weight, hip height, wither height, and average daily gain despite similar daily starter intake. Concentration of methionine in plasma was lower at birth but increased markedly at 2 and $7 \mathrm{~d}$ of age in MET calves. Plasma insulin, glucose, free fatty acids, and hydroxybutyrate did not differ. A greater ratio of phosphorylated $\alpha$-serine/threonine kinase (AKT):total AKT protein expression was detected in MET calves, namely due to differences at $4 \mathrm{~d}$ of age. The phosphorylated MTOR:total MTOR ratio also was greater in MET calves due to differences at 28 and $50 \mathrm{~d}$ ( $8 \mathrm{~d}$ postweaning). The decrease in phosphorylated MTOR:total MTOR between 14 and $28 \mathrm{~d}$ in CON calves agreed with the increase in phosphorylated eukaryotic translation initiation factor $4 \mathrm{E}$ binding pro-
\end{abstract}

Received January 2, 2018.

Accepted April 24, 2018.

${ }^{1}$ Corresponding author: jloor@illinois.edu tein 1 (EIF4EBP1):total EIF4EBP1 ratio during the same time frame. The overall expression of phosphorylated ribosomal protein S6 kinase B1 (RPS6KB1):total RPS6KB1 and phosphorylated eukaryotic translation elongation factor 2 (EEF2):total EEF2 was lower in MET calves. Regardless of methionine supply prepartum, there was an 11-fold temporal decrease from 4 to $50 \mathrm{~d}$ in phosphorylated AKT:total AKT. Similarly, regardless of methionine supply, there were overall decreases in phosphorylation ratios of AKT, MTOR, RPS6KB1, and eukaryotic translation initiation factor 2A (EIF2A) over time. Data provide evidence of a positive effect of methionine supply during the last month of pregnancy on rates of growth during the first $7 \mathrm{wk}$ of age. Phosphorylation status of some components of the MTOR pathway in neonatal calf liver also was associated with greater maternal supply of methionine. Thus, the data suggest that molecular mechanisms in the liver might be programmed by supply of methionine during late pregnancy. The exact mechanisms coordinating the observed responses remain to be determined.

Key words: ruminant, amino acid, gluconeogenesis, insulin

\section{INTRODUCTION}

A key adaptation that neonatal animals undergo is a shift in the reliance for energy on glucose, lactate, AA, and fatty acids in utero to relying on digestion of lactose to glucose, protein to AA, and fat to fatty acids via intake of colostrum and milk (Girard et al., 1992; Hammon et al., 2012). Unlike monogastrics, ruminants absorb little glucose from the gut, and both the pregnant mother and the fetus rely to various degrees on propionate and AA as gluconeogenic substrates (Stevenson et al., 1976; Prior and Christenson, 1977; Prior and Scott, 1977). In fact, a unique feature of the bovine fetal liver is the marked reliance on AA (e.g., alanine) and lactate (utilization of propionate is very low) 
for gluconeogenesis as early as $80 \mathrm{~d}$ of gestation and through term (Prior and Scott, 1977). Because voluntary feed intake of pregnant dairy cows could decrease markedly during the last $3 \mathrm{wk}$ before parturition (Loor et al., 2013), the potential effect of prepartal nutrition of the cow on the rapidly growing fetus (Ferrell, 1991) cannot be underestimated. Therefore, the beneficial effect on calf birth weight reported often when the supply of dietary protein and energy prepartum is increased is not surprising (Funston et al., 2010).

Recent data have provided some evidence that enhancing micronutrient supply (methionine, $\mathrm{Zn}, \mathrm{Cu}, \mathrm{Co}$, $\mathrm{Mn}$ ) in pregnant dairy cows during the last month of gestation can induce changes in the transcriptome of the neonatal liver (Jacometo et al., 2016, 2017) and circulating leukocytes (Jacometo et al., 2015) without markedly altering growth rate during the preweaning period. Whether the prenatal supply of micronutrients alters protein expression of nutrient-responsive signaling pathways in organs of the bovine neonate is unknown. There is evidence that methyl donor supply during pregnancy in pigs alters the epigenetic status of hepatic gluconeogenic (Cai et al., 2014b) and lipid metabolism-related genes (Cai et al., 2014a, 2016) in 1-d-old piglets. At least in ruminants, it is unknown whether such effects persist during postnatal life and whether they are related to physiologic measures of rumen development and growth.

Mammalian target of rapamycin (MTOR) is a key protein kinase that connects nutritional and hormonal signals to downstream proteins involved in various processes, including protein synthesis. Underfeeding of beef cows during early gestation reduced the concentrations of phosphorylated MTOR in both maternal and fetal skeletal muscle (Du et al., 2005). Although no published studies demonstrate a response to individual AA on MTOR signaling in neonatal bovine liver, exogenous arginine in neonatal nursing pigs increased muscle and liver protein synthesis rate, but only muscle had greater phosphorylation of MTOR (Yao et al., 2008). An in vitro study with hepatocytes also demonstrated that, as long as insulin was present, methionine and leucine both increased phosphorylation of $\alpha$-serine/threonine kinase (AKT) coupled with a decrease in mRNA expression of gluconeogenic genes (Lansard et al., 2011).

Newborn ruminants lack a functional rumen and in current production systems rely on high-fat and highprotein milk replacers for nourishment for the first weeks of life. They are gradually introduced to solid feed that is high in fiber while milk replacer is removed from the diet and are fully weaned at approximately 42 d of age (Hammon et al., 2012). Thus, not only does the profile of nutrients reaching tissues change early in life, but so do the endocrine environment (e.g., insulin, glucagon) and activity of various key hepatic enzymes (Hammon et al., 2012). In light of the unique physiologic adaptations that neonatal ruminants undergo, the present study aimed to evaluate whether maternal methionine supply was associated with hepatic metabolic gene transcription, MTOR signaling, and overall growth patterns during early life. To address our objective, we used the offspring from dairy cows that were supplemented or not with rumen-protected methionine during the last month of pregnancy (Batistel et al., 2017a).

\section{MATERIALS AND METHODS}

\section{Animals and Experimental Design}

All procedures for the current study were conducted in accordance with a protocol approved by the Institutional Animal Care and Use Committee of the University of Illinois (protocol no. 14270). Details of the maternal treatments were described previously (Batistel et al., 2017b). Briefly, 60 multiparous Holstein cows were used in a complete block design with 30 cows per treatment. Cows were fed with a basal control $(\mathbf{C O N}$; $1.47 \mathrm{Mcal} / \mathrm{kg}$ of $\mathrm{DM}, 15.6 \% \mathrm{CP}$ ) diet with no addition of methionine or the basal diet plus ethylcellulose rumen-protected methionine (MET; Mepron, Evonik Nutrition \& Care GmbH, Hanau Wolfgang, Germany) during the last $28 \pm 2$ d of pregnancy. The supplemental methionine was top-dressed on the total mixed diet at a rate of $0.09 \%$ of DMI. The methionine was supplied to achieve a lysine:methionine ratio in the MP reaching the small intestine close to 2.8:1. This rate has been demonstrated to elicit beneficial effects in terms of production performance and health (Osorio et al., 2013; Zhou et al., 2016b).

Because of their economic importance in terms of milk production, only a subset of heifer calves born to cows in the CON $(\mathrm{n}=8)$ or MET $(\mathrm{n}=8)$ groups was used (Alharthi et al., 2017). Body weight, hip and wither height, hip width, and body length were measured at birth. The navel was disinfected with a $7 \%$ tincture of iodine solution (First Priority Inc., Elgin, IL), and calves were vaccinated with TSV II (Pfizer Inc., New York, NY) via nostril application. All calves were housed and managed in the same fashion during the first $7 \mathrm{wk}$ of life. Per standard operating procedures, calves received $3.8 \mathrm{~L}$ of first-milking colostrum within $6 \mathrm{~h}$ after birth. Calves were housed in individual outdoor hutches bedded with straw and fed twice daily (0700 and $1800 \mathrm{~h}$ ) with a milk replacer (Advance Excelerate, Milk Specialties, Carpentersville, IL; $28.5 \%$ CP, 
$15 \%$ fat) until $35 \mathrm{~d}$ of age. They were then switched to once-daily feeding at $0700 \mathrm{~h}$ until weaning ( $42 \mathrm{~d}$ of age). Calves received $4.54 \mathrm{~kg} / \mathrm{d}$ of milk replacer mix $(0.59 \mathrm{~kg}$ of milk replacer in $3.95 \mathrm{~L}$ of water) from 1 to $10 \mathrm{~d}$ of age, $5.90 \mathrm{~kg} / \mathrm{d}(0.77 \mathrm{~kg}$ of milk replacer in 5.13 $\mathrm{L}$ of water) from 11 to $20 \mathrm{~d}$ of age, $7.26 \mathrm{~kg} / \mathrm{d}(0.94 \mathrm{~kg}$ of milk replacer in $6.32 \mathrm{~L}$ of water) from 21 to $35 \mathrm{~d}$ of age, and $3.63 \mathrm{~kg} / \mathrm{d}(0.47 \mathrm{~kg}$ of milk replacer in $3.16 \mathrm{~L}$ of water) from 36 to $42 \mathrm{~d}$ of age. From d 1 until 56 of life, calves had ad libitum access to a starter grain mix $(19.9 \%$ CP, $13.5 \%$ NDF) fed at 0800 h. All the milk replacer was consumed each day by the calves. Fecal score (scale 1-4), respiratory score (scale 1-5), and rectal temperature were measured weekly, and starter intake was recorded daily until $56 \mathrm{~d}$ of age. Body weight, hip height, wither height, and hip width were recorded once a week from birth until 8 wk of age. Average daily gain was recorded as final $\mathrm{BW}$ - initial $\mathrm{BW} /$ days on study (0-56 d of age).

\section{Blood Sampling and Biomarker Concentrations}

Blood samples were collected from the jugular vein before feeding at 0 (birth, before colostrum), 2, 7, 21, 42 , and $50 \mathrm{~d}$ of age using 20-gauge BD Vacutainer needles (Becton Dickinson, Franklin Lakes, NJ). The Vacutainer tubes used contained lithium heparin, and plasma was obtained by centrifugation at $1,900 \times g$ for $15 \mathrm{~min}$ at $4^{\circ} \mathrm{C}$ and stored at $-80^{\circ} \mathrm{C}$ until further analysis.

Samples were used for measuring concentrations of albumin (catalog no. 0018250040), glucose (catalog no. 0018250840), urea (catalog no. 0018255440), and cholesterol (catalog no. 0018250540) using kits from Instrumentation Laboratory Spa (Werfen Co., Milan, Italy) for use in the ILAB 600 clinical autoanalyzer (Instrumentation Laboratory, Lexington, MA). Concentrations of nonesterified fatty acids (NEFA) and BHB were determined as described previously (Osorio et al., 2013). Plasma insulin concentrations were determined using a bovine-specific commercial ELISA kit (catalog no. 10-1201-01; Mercodia, Uppsala, Sweden).

\section{AA Analysis}

Plasma, colostrum (Supplemental Table S1; https:/ doi.org/10.3168/jds.2018-14378), and starter (Supplemental Table S2; https://doi.org/10.3168/jds.2018 -14378) AA concentration analysis was performed according to established protocols (AOAC International, 1995). The starter and milk replacer samples were obtained weekly during the first 6 wk of age. Briefly, samples were first oxidized at $0^{\circ} \mathrm{C}$ for $16 \mathrm{~h}$ with per- formic acid to allow for subsequent quantification of methionine and cystine. Excess performic acid was removed with an incubation with sodium sulfite for 30 min in an ice bath. Hydrolysis was then performed with hydrochloric acid at $110^{\circ} \mathrm{C}$ for $24 \mathrm{~h}$. A Biochrom $30+$ (Biochrom Ltd., Cambridge, UK) AA analyzer was used for AA profiling.

\section{Liver Biopsies}

Liver biopsies ( $\mathrm{n}=8$ per treatment) were harvested at $4,14,28$, and $50 \mathrm{~d}$ of age under local anesthesia using the same procedures as described previously (Jacometo et al., 2017). Liver samples were frozen immediately in liquid nitrogen and stored at $-80^{\circ} \mathrm{C}$ until further analysis.

\section{RNA Extraction, cDNA Synthesis, and Quantitative PCR}

The procedures of RNA isolation, cDNA synthesis, and quantitative PCR are described in detail in Supplemental File S1 (https://doi.org/10.3168/jds .2018-14378). Briefly, RNA was extracted from frozen tissue from each calf ( $\mathrm{n}=8$ per treatment) and used for cDNA synthesis using established protocols (VailatiRiboni et al., 2016). The quality of RNA evaluated by RNA integrity number in the 2100 Bioanalyzer (Agilent Technologies Inc., Santa Clara, CA) was $>7.0$ for all samples. The genes GAPDH, RPS9, and UXT were used as internal control genes. The geometric mean of the internal control genes was used to normalize the expression data. A 6-point standard curve was used for quantification. Quantitative PCR performance and primer information are included in Supplemental Tables S3 and S4 (https://doi.org/10.3168/jds.2018-14378).

\section{Western Blotting}

Protocols used were the same as those reported previously (Batistel et al., 2017a). Details can be found in Supplemental File S1 (https://doi.org/10.3168/jds .2018-14378). Briefly, samples from the same calves (n $=8$ per treatment) used for gene expression analysis were used for protein expression analysis.

\section{Statistics}

The temporal plasma, mRNA, and protein expression data and performance and health data were analyzed using the MIXED procedure of SAS version 9.4 (SAS Institute Inc., Cary, NC) with repeated measures. Normalized mRNA and protein expression data were $\log 2$ 
transformed before statistical analysis. The following model was used:

$$
Y_{j l}=\mu+T_{j}+D_{l}+D T_{j l}+\varepsilon_{j l},
$$

where $Y_{j l}$ is the dependent continuous variable, $\mu$ is the overall mean, $T_{j}$ is the fixed effect of treatment $(j$ is the maternal treatment CON or MET), $D_{l}$ is the fixed effect of day of age, $D T_{j l}$ is the interaction between maternal treatment and day of age, and $\varepsilon_{j l}$ is the residual error. Calf, nested within maternal treatment, was the random effect. The Kenward-Roger statement was used for computing the denominator degrees of freedom. The covariance structure of the repeated measurements was spatial power $[\mathrm{SP}(\mathrm{POW})]$ for all blood biomarkers, mRNA abundance, and protein abundance or first-order autoregressive structure $[\mathrm{AR}(1)]$ for the growth data. When the interaction was significant, least squares means separation between and within time points was performed using the PDIFF statement with Tukey adjustment. No multiple testing correction of the $P$-values of the blood biomarker data was performed. To evaluate the potential for starter intake as a driving force of differences in growth rate, starter intake data from 1 to $34 \mathrm{~d}$ of age and from 35 to $56 \mathrm{~d}$ of age were analyzed separately. Amino acid profiles of fat-free colostrum (Supplemental Table S1; https://doi.org/10 .3168/jds.2018-14378) were analyzed using the MIXED procedure without repeated measures. The AA profiles, ammonia, and CP content of starter and milk replacer were not analyzed statistically (Supplemental Table S2; https://doi.org/10.3168/jds.2018-14378). Normality of the residuals was checked with normal probability and box plots, and homogeneity of variances was checked with plots of residuals versus predicted values.

\section{RESULTS}

\section{Growth Performance and Health in Calves}

Main effects of maternal diet, time, and their interactions over the first $9 \mathrm{wk}$ of life are presented in Table 1. Calves from cows fed MET had a greater $(P$ $\leq 0.05$ ) average BW, hip height, wither height, and ADG. When analyzing daily starter intake from $d 1$ to 34 of age (data not shown), there was no overall effect of maternal diet $(P=0.27)$ or interaction of maternal diet and time $(P=0.20)$, but there was a time effect ( $P$ $<0.01)$. Similarly, when analyzing daily starter intake from d 35 to 56 of age (data not shown), there was no overall effect of maternal diet $(P=0.18)$ or interaction of maternal diet and time $(P=0.45)$, but there was a time effect $(P<0.01)$. Hip width, body length, and starter intake were not affected $(P>0.05)$ by maternal diet. Similarly, there was no overall maternal diet effect for feed efficiency $(P=0.68)$, rectal temperature $(P=$ $0.65)$, and respiratory score $(P=0.27)$. There was a maternal diet $\times$ day effect $(P=0.05)$ due to greater BW and lower fecal score $(P=0.01)$ in calves from cows fed MET compared with CON (Table 2, Figure $1)$.

\section{Concentrations of Biomarkers in Blood Plasma}

Maternal diet led to a significant treatment $\times$ day $(P<0.01)$ interaction for glucose as a result of lower (Tukey-adjusted $P=0.01$ ) concentration on $\mathrm{d} 2$ and greater (Tukey-adjusted $P=0.01$ ) concentration on d 42 in MET compared with CON calves (Figure 2). There was no overall effect $(P>0.05)$ of maternal MET supply on the concentrations of BHB and NEFA. However, concentrations of cholesterol and albumin were greater overall $(P=0.05)$ in MET compared with CON calves. Day of age had an effect on all these parameters (glucose, cholesterol, urea, BHB, albumin, NEFA, ceruloplasmin; day, $P<0.01$; Supplemental Figure S1, https://doi.org/10.3168/jds.2018-14378) due to increases of cholesterol, urea, BHB, and albumin and decreases of glucose and NEFA during the experimental period.

\section{AA Concentrations in Blood Plasma}

There were no significant $(P<0.05)$ main effects of maternal treatment for any AA or AA-related compound measured (Table 1). The profiles of selected AA in blood plasma are shown in Figure 3 and Supplemental Figure S2 (https://doi.org/10.3168/jds.2018 $-14378)$. There was an interaction of treatment $\times$ day $(P \leq 0.05)$ for the concentrations of arginine, histidine, methionine, and phenylalanine (Table 1, Figure 3). Arginine concentration increased markedly in CON calves from birth to $7 \mathrm{~d}$ of age, whereas it remained stable in MET calves during that time frame followed by a marked increase in concentration between $\mathrm{d} 7$ and 21 (Figure 3). Although concentration of histidine was lower (Tukey-adjusted $P=0.01$ ) at birth in CON calves compared with MET calves, it increased markedly at d 2 followed by a decrease to almost baseline concentration on $\mathrm{d} 7$ through the end of the study. In contrast to the histidine profile, the concentration of methionine in CON calves was lower at birth (Tukey-adjusted $P$ $=0.01$ ), but at d 2 MET calves had greater (Tukeyadjusted $P=0.01$ ) concentrations. Concentrations of methionine in both groups subsequently decreased over time. For phenylalanine, a marked decrease (Tukey- 
adjusted $P=0.01$ ) in concentration between birth and d 2 in MET calves was detected, whereas a decrease in concentration between d 7 and 21 was observed for CON compared with MET calves.

Regardless of maternal diet, concentrations of all AA, ornithine, 1-methylhistidine, and 3-methylhistadine had a significant day effect $(P<0.05$; Supplemental Figures S2 and S3; https://doi.org/10.3168/jds .2018-14378). Among these compounds, concentrations of lysine, threonine, arginine, isoleucine, leucine, and asparagine increased gradually to almost peak levels at 21 d of age (Supplemental Figures S2 and S3). Concentrations of glutamate, asparagine, and valine reached a peak at $2 \mathrm{~d}$ of age and remained stable afterward. Concentrations of glycine, methionine, alanine, and taurine were greater at birth and decreased gradually afterward. Ornithine concentration increased gradually from birth to peak levels at d 50 of age. In contrast, concentrations of 1-methylhistidine and 3-methylhistidine decreased over time from peak levels at birth to a nadir at $21 \mathrm{~d}$ of age.

\section{Metabolic Gene Expression}

Among the target genes measured, few had significant changes in response to maternal supply of methionine (Table 3 and Supplemental Figure S4; https:// doi.org/10.3168/jds.2018-14378). Among carbohydrate metabolism-related genes, there was a treatment $\times$ day $(P=0.05)$ effect for the expression of forkhead box $\mathrm{O} 1$ (FOXO1) due to downregulation between d 4 and 14 in the CON compared with MET calves (Supplemental Figure S4). Expression of insulin receptor substrate 1 (IRS1) also had a significant interaction (treatment $\times$

Table 1. Blood plasma biomarkers and free AA from birth through $56 \mathrm{~d}$ of age in heifer calves born to Holstein cows fed during the last $28 \mathrm{~d}$ of pregnancy a control diet $(\mathrm{CON}, \mathrm{n}=18)$ or the control diet supplemented with ethylcellulose rumen-protected methionine $(\mathrm{MET}$, $\mathrm{n}=21 ; 0.09 \%$ DMI; Mepron, Evonik Nutrition \& Care GmbH, Hanau Wolfgang, Germany) ${ }^{1}$

\begin{tabular}{|c|c|c|c|c|c|c|}
\hline \multirow[b]{2}{*}{ Item } & \multicolumn{2}{|c|}{ Maternal treatment } & \multirow[b]{2}{*}{ SEM } & \multicolumn{3}{|c|}{$P$-value ${ }^{2}$} \\
\hline & $\mathrm{CON}$ & MET & & $\mathrm{T}$ & $\mathrm{D}$ & $\mathrm{T} \times \mathrm{D}$ \\
\hline \multicolumn{7}{|l|}{ Plasma biomarkers } \\
\hline Insulin $(\mu \mathrm{g} / \mathrm{L})$ & 0.45 & 0.51 & 0.06 & 0.53 & $<0.01$ & 0.61 \\
\hline Glucose (mmol/L) & 6.75 & 7.13 & 0.23 & 0.25 & $<0.01$ & $<0.01$ \\
\hline $\mathrm{BHB}(\mathrm{mmol} / \mathrm{L})$ & 0.09 & 0.10 & 0.006 & 0.65 & $<0.01$ & 0.77 \\
\hline Nonesterified fatty acids (mmol/L) & 0.22 & 0.23 & 0.01 & 0.79 & $<0.01$ & 0.13 \\
\hline Urea $(\mathrm{mmol} / \mathrm{L})$ & 4.66 & 4.57 & 0.15 & 0.69 & $<0.01$ & 0.26 \\
\hline Cholesterol (mmol/L) & 1.39 & 1.53 & 0.04 & 0.05 & $<0.01$ & 0.55 \\
\hline Albumin $(\mathrm{g} / \mathrm{L})$ & 31.1 & 32.1 & 0.35 & 0.05 & $<0.01$ & 0.61 \\
\hline Ceruloplasmin $(\mu \mathrm{mol} / \mathrm{L})$ & 1.16 & 1.31 & 0.10 & 0.34 & $<0.01$ & 0.93 \\
\hline \multicolumn{7}{|l|}{ Plasma AA $(\mathrm{mg} / \mathrm{dL})$} \\
\hline \multicolumn{7}{|l|}{ Nondispensable } \\
\hline Arginine & 1.86 & 2.10 & 0.12 & 0.21 & $<0.01$ & $<0.01$ \\
\hline Histidine & 0.98 & 1.06 & 0.05 & 0.31 & $<0.01$ & $<0.01$ \\
\hline Isoleucine & 1.25 & 1.43 & 0.08 & 0.14 & $<0.01$ & 0.36 \\
\hline Leucine & 1.85 & 2.14 & 0.11 & 0.06 & $<0.01$ & 0.24 \\
\hline Lysine & 1.22 & 1.26 & 0.07 & 0.77 & $<0.01$ & 0.10 \\
\hline Methionine & 0.30 & 0.33 & 0.02 & 0.46 & $<0.01$ & 0.05 \\
\hline Phenylalanine & 0.68 & 0.73 & 0.03 & 0.46 & $<0.01$ & $<0.01$ \\
\hline Threonine & 1.21 & 1.20 & 0.06 & 0.95 & $<0.01$ & 0.14 \\
\hline Valine & 2.61 & 2.90 & 0.13 & 0.15 & $<0.01$ & 0.60 \\
\hline \multicolumn{7}{|l|}{ Dispensable } \\
\hline Asparagine & 0.47 & 0.48 & 0.02 & 0.78 & $<0.01$ & 0.16 \\
\hline Aspartate & 0.13 & 0.14 & 0.01 & 0.42 & $<0.01$ & 0.47 \\
\hline Alanine & 2.19 & 2.20 & 0.11 & 0.95 & $<0.01$ & 0.34 \\
\hline Glutamine & 4.27 & 4.54 & 0.20 & 0.36 & $<0.01$ & 0.15 \\
\hline Glutamate & 0.82 & 0.93 & 0.03 & 0.10 & $<0.01$ & 0.19 \\
\hline Glycine & 2.09 & 2.14 & 0.12 & 0.80 & $<0.01$ & 0.27 \\
\hline Ornithine & 0.62 & 0.68 & 0.04 & 0.32 & $<0.01$ & 0.33 \\
\hline Proline & 1.21 & 1.20 & 0.05 & 0.92 & $<0.01$ & 0.36 \\
\hline Serine & 0.81 & 0.80 & 0.04 & 0.94 & $<0.01$ & 0.17 \\
\hline Taurine & 0.93 & 1.05 & 0.05 & 0.16 & $<0.01$ & 0.17 \\
\hline Tyrosine & 0.80 & 0.85 & 0.03 & 0.31 & $<0.01$ & 0.14 \\
\hline 1-Methylhistidine & 0.39 & 0.36 & 0.03 & 0.40 & $<0.01$ & 0.09 \\
\hline 3-Methylhistidine & 0.08 & 0.07 & 0.01 & 0.34 & $<0.01$ & 0.91 \\
\hline
\end{tabular}

${ }^{1}$ All calves were fed first-milking colostrum from their respective dams within $6 \mathrm{~h}$ postbirth. All calves received the same milk replacer until weaning at $\mathrm{d} 42$ of age.

${ }^{2} P$-value for treatment $(\mathrm{T})$, day $(\mathrm{D})$, and their interaction $(\mathrm{T} \times \mathrm{D})$. 
Table 2. Feed intake, growth, ADG, and health parameters from birth through $56 \mathrm{~d}$ of age in heifer calves born to Holstein cows fed during the last $28 \mathrm{~d}$ of pregnancy a control diet $(\mathrm{CON}, \mathrm{n}=18)$ or the control diet supplemented with ethylcellulose rumen-protected methionine (MET, $\mathrm{n}$ $=21 ; 0.09 \%$ DMI; Mepron, Evonik Nutrition \& Care GmbH, Hanau Wolfgang, Germany) ${ }^{1}$

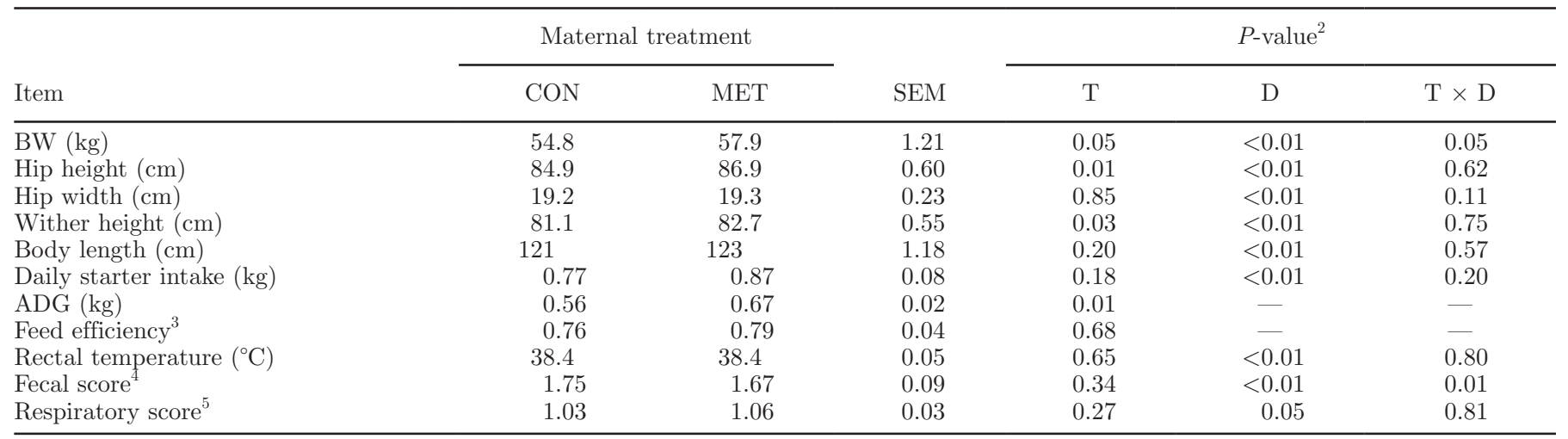

${ }^{1}$ All calves were fed first-milking colostrum from their respective dams within $6 \mathrm{~h}$ postbirth. All calves received the same milk replacer until weaning at $\mathrm{d} 42$ of age.

${ }^{2} P$-value for treatment $(\mathrm{T})$, day $(\mathrm{D})$, and their interaction $(\mathrm{T} \times \mathrm{D})$.

${ }^{3}$ Calculated as total gain/total DMI.

${ }^{4}$ Based on appearance: 1 = firm, well formed; $2=$ soft, pudding-like; $3=$ runny, package batter; $4=$ liquid, splatters.

${ }^{5}$ Based on appearance: $1=$ normal; $2=$ runny nose; $3=$ heavy breathing; $4=$ cough moist; $5=$ cough dry.

day, $P=0.05)$ due to lower expression at $\mathrm{d} 4$ in MET compared with CON calves. Regardless of maternal supply of methionine, expression of fatty acid synthase $(\boldsymbol{F A} \boldsymbol{S N})$ and the lipogenic transcription factor sterol regulatory element binding transcription factor 1 (SREBF1) increased over time in both groups $(P<$ 0.01).

Among gluconeogenic-related genes, a marked upregulation in the expression of phosphoenolpyruvate carboxykinase 1 (PCK1) between d 28 and 50 in the CON versus MET calves led to a significant interaction effect (treatment $\times$ day, $P=0.02$ ). Maternal supply of methionine led to lower overall expression of pyruvate carboxylase $(\boldsymbol{P C} ; P<0.05)$, and expression of this gene decreased gradually from d 4 until d 28 in both groups $(P<0.01)$. Furthermore, expression of glucose6-phosphatase $(\boldsymbol{G 6 P C})$ decreased from d 4 to d 14 and then increased from d 14 until d 50 of age $(P<0.01)$. There was no day effect on the expression of phosphoenolpyruvate carboxykinase 2 (PCK2; mitochondrial isoform) in both groups, whereas overall expression of PCK1 increased gradually from d 4 to d 28 .

Among genes related to the MTOR pathway, there was an overall effect of maternal MET supply in the expression of eukaryotic translation elongation factor 2 (EEF2) and ribosomal protein S6 (RPS6) due to lower overall values in MET compared with CON calves (Table 1). No maternal MET effect $(P>0.06)$ was detected for the expression of AKT, MTOR, ribosomal protein S6 kinase B1 (RPS6KB1), and eukaryotic translation initiation factor $4 \mathrm{E}$ binding protein
1 (EIF4EBP1). Although day of age had no effect on MTOR and RPS6KB1 expression, EIF $4 E B P 1$ and EEF2 expression decreased between d 4 and d 50 in both groups.

\section{Expression of Proteins Related to Insulin Signaling and the MTOR Pathway}

The expression of proteins and phosphorylation status related to the MTOR pathway in the liver of calves is reported in Figures 4, 5, and 6. There was a treatment $\times$ day $(P<0.01)$ effect for total AKT, phosphorylated (p) AKT and p-AKT:total AKT ratio (Figure 4). Total abundance of AKT protein decreased markedly between $\mathrm{d} 4$ and 14 in CON calves, whereas it increased in MET calves and remained higher through d 28. Level of p-AKT on d 14, 28, and 50 (treatment $\times$ day, $P<0.01$ ) was greater in MET compared with CON calves. As a result of these temporal changes, the p-AKT:total AKT ratio on d 4 and 50 was greater (treatment $\times$ day, $P<0.01$ ) in MET compared with CON calves.

Although maternal MET supplementation did not alter total MTOR protein expression $(P=0.80)$, expression of $\mathrm{p}$-MTOR (treatment $\times$ day, $P<0.01$ ) and $\mathrm{p}$ -MTOR:total MTOR ratio (treatment, $P=0.02$ ) were greater overall in MET than in CON calves due primarily to lower values in CON calves on d 28 and 50 of age (Figure 5). Total RPS6KB1 protein expression was lower on d 4 (treatment $\times$ day, $P<0.01$ ) but greater on d 28 and 50 in MET than in CON calves. However, 

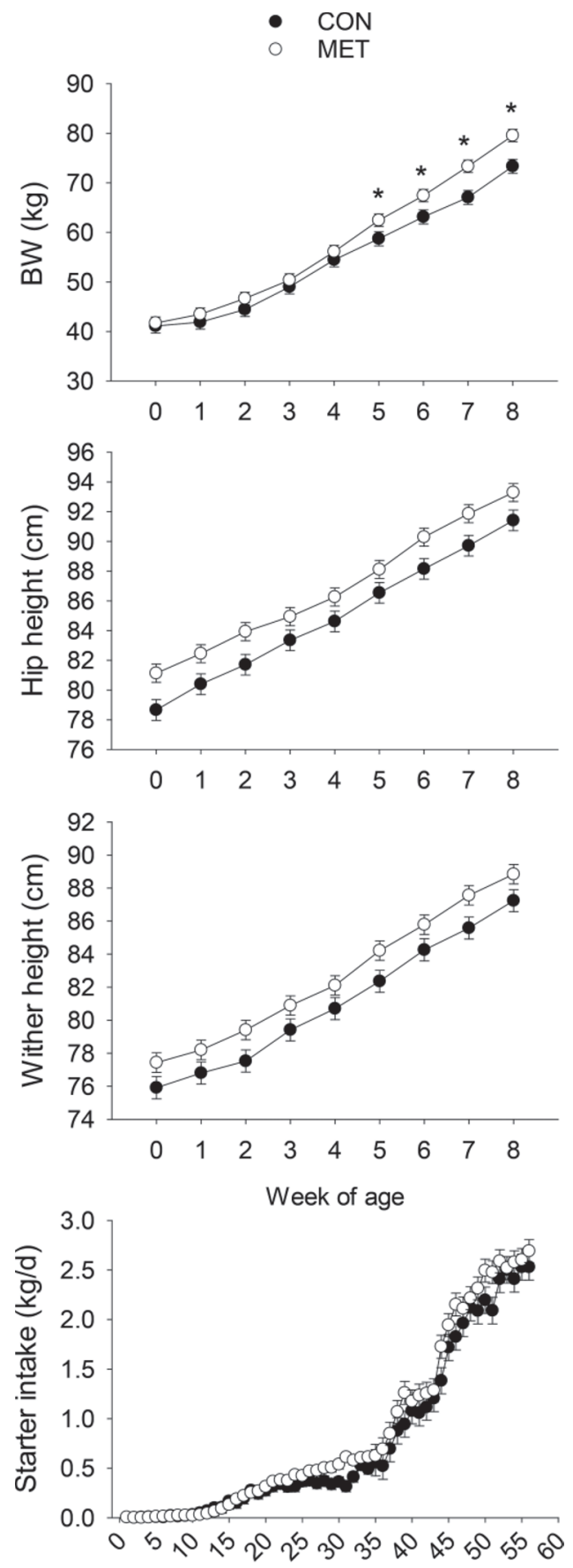

Day of age

Figure 1. Maternal treatment $\times$ time response on BW, hip height, wither height, and daily starter intake in heifer calves born to Holstein cows fed during the last $28 \mathrm{~d}$ of pregnancy a control diet $(\mathrm{CON}, \mathrm{n}$ $=18$ ) or the control diet supplemented with ethylcellulose rumenprotected methionine (MET, $\mathrm{n}=21 ; 0.09 \%$ DMI; Mepron, Evonik Nutrition \& Care GmbH, Hanau Wolfgang, Germany). Values are means \pm SEM. Body weight: maternal treatment $P=0.05$, time $P<$ 0.01 , and maternal treatment $\times$ time $P=0.05$. Hip height: maternal treatment $P=0.01$, time $P<0.01$, and maternal treatment $\times$ time $P$ $=0.63$. Wither height: maternal treatment $P=0.03$, time $P<0.01$, and maternal treatment $\times$ time $P=0.74$. Asterisk $\left(^{*}\right)$ indicates that means differ; treatment $\times$ day $P<0.05$.
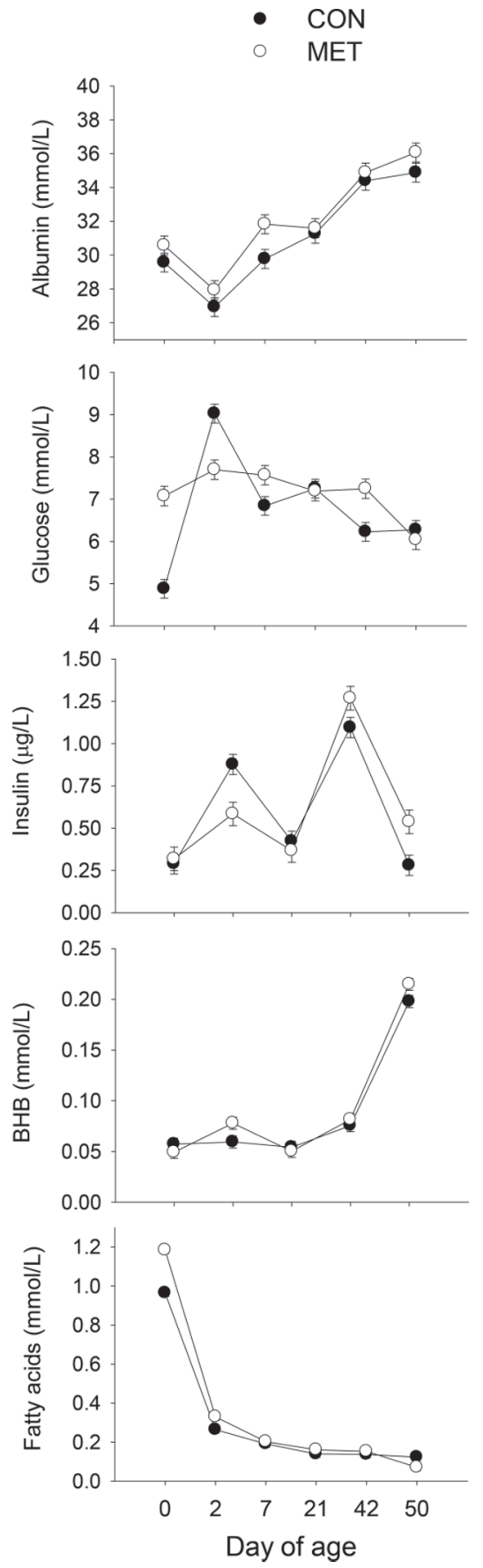

Figure 2. Plasma concentration of albumin, glucose, insulin, BHB, and fatty acids in calves born to cows fed a basal control diet (CON) or the basal diet plus ethylcellulose rumen-protected methionine (MET; $0.09 \%$ of DMI; Mepron, Evonik Nutrition \& Care GmbH, Hanau Wolfgang, Germany) during the last $28 \mathrm{~d}$ of pregnancy. All calves were fed first-milking colostrum from their respective dams within $6 \mathrm{~h}$ postbirth. All calves received the same milk replacer until weaning at 42 $\mathrm{d}$ of age. Values are means \pm SEM. There was a significant day effect $(P<0.01)$ for all biomarkers. Albumin: maternal treatment $P=0.05$, maternal treatment $\times$ time $P=0.61$. Glucose: maternal treatment $P$ $=0.25$, maternal treatment $\times$ time $P<0.01$. Insulin: maternal treatment $P=0.53$, maternal treatment $\times$ time $P=0.61$. BHB: maternal treatment $P=0.65$, maternal treatment $\times$ time $P=0.77$. Fatty acids: maternal treatment $P=0.79$, maternal treatment $\times$ time $P=0.13$. 


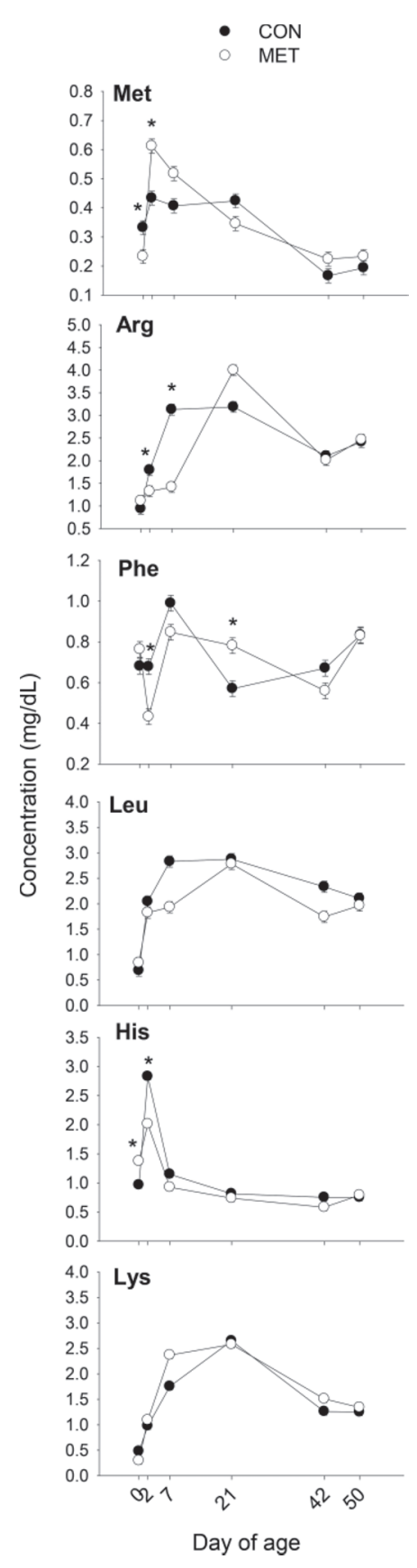

Figure 3. Amino acid profiles in plasma from calves born to cows fed a basal control diet (CON) or the basal diet plus ethylcellulose rumen-protected methionine (MET; 0.09\% of DMI; Mepron, Evonik Nutrition \& Care GmbH, Hanau Wolfgang, Germany) during the last $28 \mathrm{~d}$ of pregnancy. All calves were fed first-milking colostrum from their respective dams within $6 \mathrm{~h}$ postbirth. All calves received the same milk replacer until weaning at $42 \mathrm{~d}$ of age. Values are means \pm SEM. Asterisk $(*)$ indicates that means differ, day $\times$ treatment $P<0.05$. There was a significant day effect $(P<0.01)$ for all AA. Methionine: maternal treatment $P=0.46$, maternal treatment $\times$ time $P=0.05$. Arginine: maternal treatment $P=0.21$, maternal treatment $\times$ time $P<0.01$. Phenylalanine: maternal treatment $P=0.46$, maternal treatment $\times$ time $P<0.01$. Leucine: maternal treatment $P=0.06$, maternal treatment $\times$ time $P=0.24$. Histidine: maternal treatment $P$ $=0.31$, maternal treatment $\times$ time $P<0.01$. Lysine: maternal treatment $P=0.77$, maternal treatment $\times$ time $P=0.10$. both the level of p-RPS6KB1 and the p-RPS6KB1: total RPS6KB1 ratio (treatment, $P \leq 0.01$ ) were lower overall in MET compared with CON calves. There was an overall greater expression (treatment, $P<0.01$ ) of total RPS6 in MET compared with CON calves, but p-RPS6 and p-RPS6:total RPS6 ratio were not affected by maternal MET.

The expression of total EIF4EBP1 was overall greater (treatment, $P=0.02$ ) in MET compared with CON calves, namely due to 3 -fold greater expression at $28 \mathrm{~d}$ of age (Figure 5). The level of p-EIF4EBP1 on d 28 in MET compared with CON calves was also greater (treatment $\times$ day, $P=0.06$ ). These responses led to a treatment $\times$ day $(P<0.01)$ interaction in the p-EIF4EBP1:total EIF4EBP1 ratio, namely due to a marked increase between d 14 and 28 of age in CON compared with MET calves.

There was a treatment $\times$ day $(P<0.01)$ interaction for total and phosphorylated eukaryotic translation initiation factor 2A (EIF2A), namely as a result of lower expression on d 4 in MET compared with CON calves (Figure 6$)$. There was a treatment $\times$ day $(P<$ 0.01) interaction for the expression of total EEF2 due primarily to a marked decrease between d 4 and 14 in CON compared with MET calves such that expression was greater in MET calves on d 14. The phosphorylation of EEF2 had a treatment $\times$ day interaction $(P=$ 0.03 ) primarily due to a 2.4 -fold greater level in CON compared with MET calves on d 4 of age. These responses led to an overall lower $(P<0.01)$ p-EEF2:total EEF2 ratio in MET compared with CON calves.

Besides maternal effects or interactions, a day effect was associated with decreases in phosphorylation ratios for AKT, MTOR, RPS6KB1, and EIF2 regardless of maternal treatment (Supplemental Figure S5; https:// doi.org/10.3168/jds.2018-14378). In contrast, phosphorylation ratios for RPS6, EIF4EBP1, and EEF2 expression increased over time regardless of maternal treatment (Supplemental Figure S5; https://doi.org/10 .3168/jds.2018-14378).

\section{DISCUSSION}

Except for phenylalanine, glutamine, glycine, and serine, the plasma concentration of methionine and other indispensable AA increases prepartum in dairy cows when the dietary supply of methionine is increased (Zhou et al., 2016a; Batistel et al., 2017a). A similar response was detected in cows from the present study (Batistel et al., 2017a, b), hence providing the opportunity to evaluate postnatal effects of maternal methionine supply on measures of calf growth and metabolism. That few measures of development and metabolism at birth differed in MET compared with CON 
Table 3. Messenger RNA expression of genes related to insulin signaling, gluconeogenesis, and the mammalian target of rapamycin signaling pathway in liver tissue from calves born to cows fed a basal control diet (CON) or the basal diet plus ethylcellulose rumen-protected methionine (MET; $0.09 \%$ of DMI; Mepron, Evonik Nutrition \& Care GmbH, Hanau Wolfgang, Germany) during the last $28 \mathrm{~d}_{\text {of }}$ pregnancy ${ }^{1}$

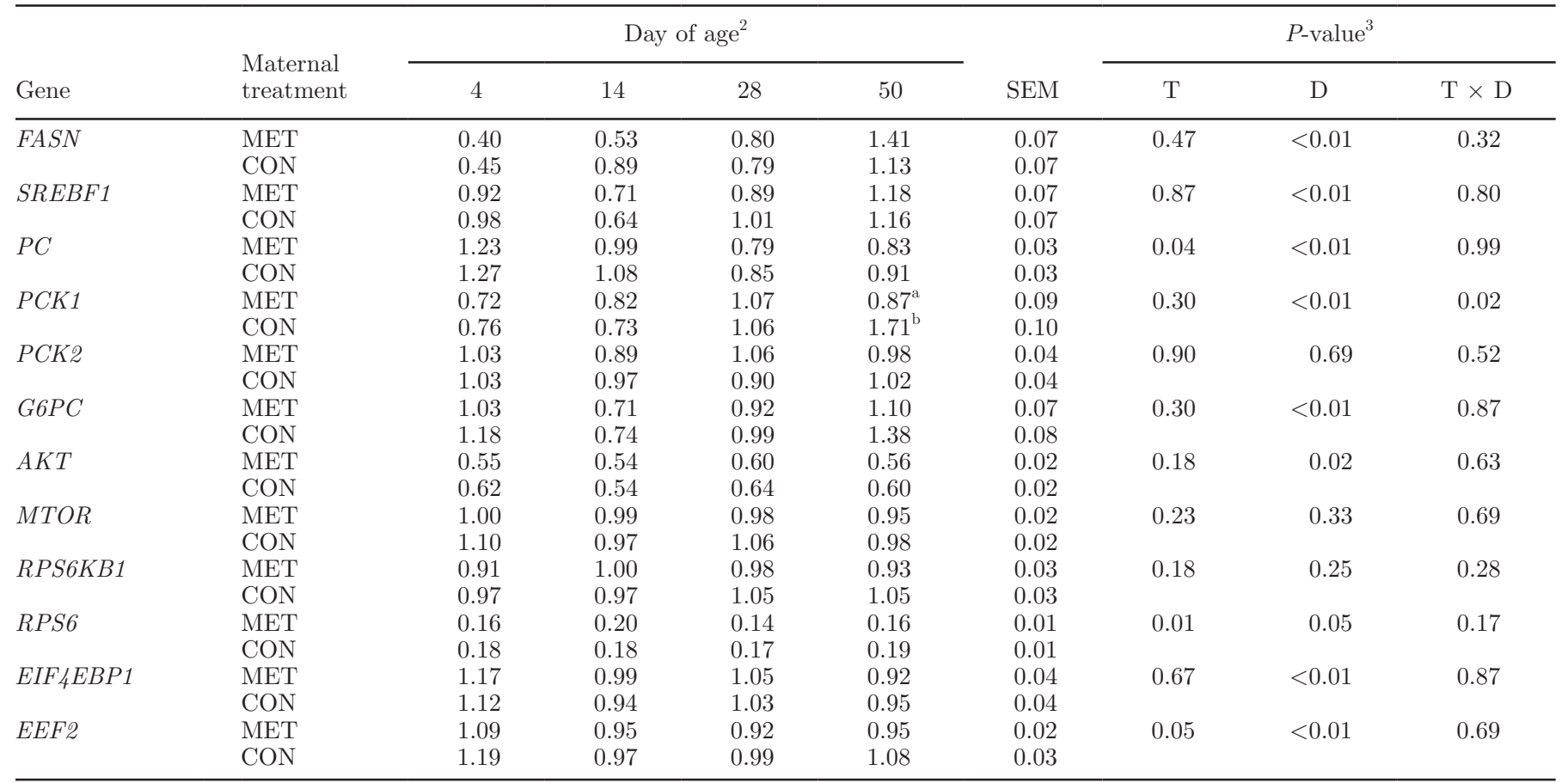

${ }^{\mathrm{a}, \mathrm{b}}$ Means within a column with different superscripts differ $(\mathrm{T} \times \mathrm{D}, P<0.05)$.

${ }^{1}$ All calves were fed first-milking colostrum from their respective dams within $6 \mathrm{~h}$ postbirth. All calves received the same milk replacer until weaning at $\mathrm{d} 42$ of age.

${ }^{2}$ Data are $\operatorname{LSM} \pm \operatorname{SEM}(\mathrm{n}=8 /$ treatment $)$.

${ }^{3} P$-value for treatment $(\mathrm{T})$, day $(\mathrm{D})$, and their interaction $(\mathrm{T} \times \mathrm{D})$.

calves and that MET calves achieved greater BW, hip height, wither height, and ADG without consuming a higher level of starter during the first 7 wk of age were suggestive of a programming effect induced in utero at least in part by the greater methionine supply. Hence, as a well-established "nutrient sensing" (Laplante and Sabatini, 2009) pathway in nonruminants, the focus of the current molecular analyses was on the role of the hepatic MTOR pathway in coordinating some of the whole-animal responses detected.

In milk-fed calves, the maturation of hepatic gluconeogenesis is partly a function of availability of lactate and AA (Hammon et al., 2012). Although systemic concentrations of glucose are clearly affected by meal patterns, the longitudinal decrease in glucose and insulin concentrations over the first $50 \mathrm{~d}$ of age in both groups partly reflects the gradual decrease in milk replacer intake and the greater intake of solid feed. The latter would have a greater effect on systemic glucose concentrations as the time of weaning approaches through the provision of propionate from ruminal fermentation. More specific indicators of a gradual development in ruminal function and changes in availability of fuels to tissues are the gradual decrease in NEFA (due to alterations in lipolysis of fat mass) and the marked temporal increase in BHB produced from ruminal ketogenesis of butyrate (Lane et al., 2002; Khan et al., 2007; Naeem et al., 2012). Clearly, there are limitations in measuring glucose and insulin at a single time point on any given day in terms of understanding residual effects of maternal MET on neonatal metabolism. However, we believe that using those data along with molecular changes over time in a metabolically important tissue such as the liver could provide a preliminary evaluation of maternal effects of methionine supply on physiologic response of the offspring.

As building blocks for proteins and substrates for gluconeogenesis (i.e., pyruvate and oxaloacetate) or fatty acids (i.e., acetyl-CoA), the AA play important roles in regulating the metabolism, growth, development, and immunity of organisms (Wu, 2013). In addition to metabolic pathways, methionine contributes approximately $50 \%$ to transmethylation reactions in neonatal piglets, with the proportion reduced to approximately $30 \%$ at 


\section{AKT}

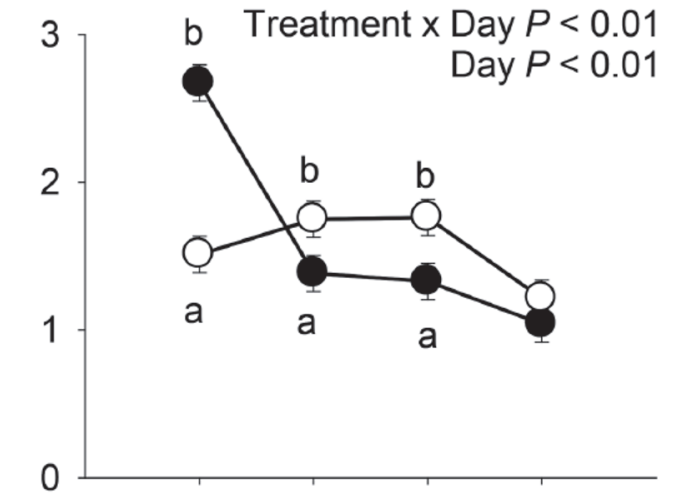

\section{p-AKT}

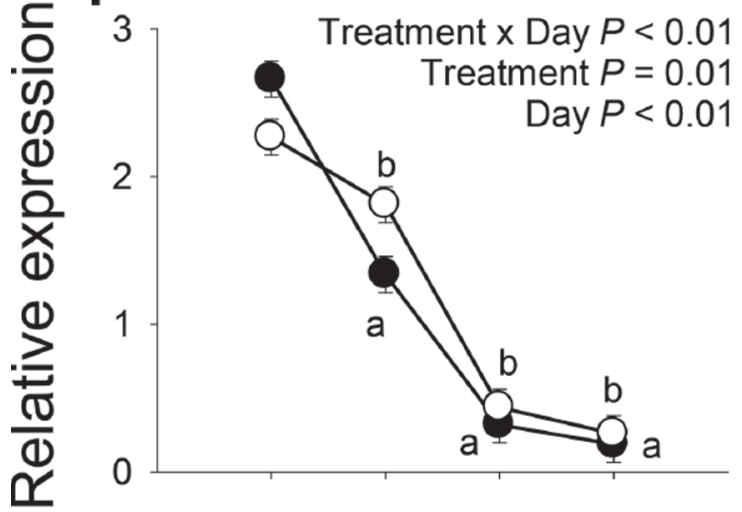

\section{p-AKT:AKT}

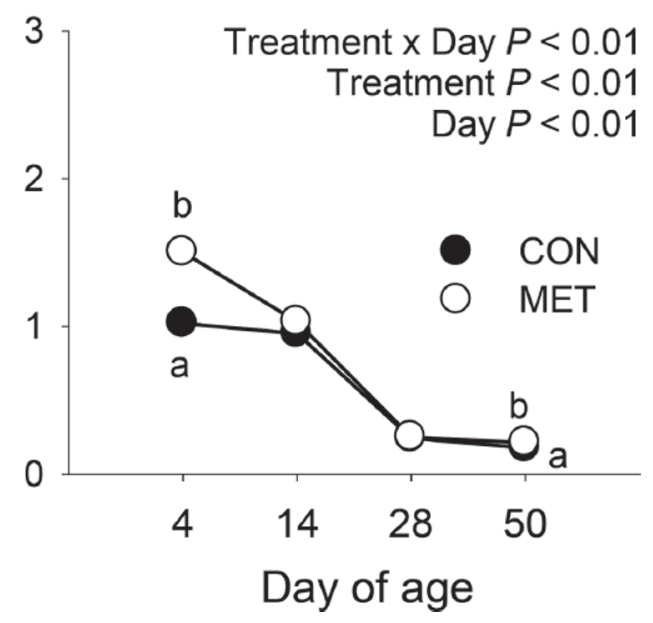

Figure 4. Abundance of total $\alpha$-serine/threonine kinase (AKT) protein, phosphorylated (p) AKT, and ratio of phosphorylated AKT to total AKT protein in the liver of calves born to cows fed a basal control diet $(\mathrm{CON})$ or the basal diet plus ethylcellulose rumen-protected methionine (MET; 0.09\% of DMI; Mepron, Evonik Nutrition \& Care GmbH, Hanau Wolfgang, Germany) during the last $28 \mathrm{~d}$ of pregnancy. All calves were fed first-milking colostrum from their respective dams within $6 \mathrm{~h}$ postbirth. All calves received the same milk replacer until weaning at $42 \mathrm{~d}$ of age. Values are means \pm SEM. Total AKT protein: maternal treatment $P=0.71$. Means with different letters (a, b) differ $(P<0.05)$ weaning (Bauchart-Thevret et al., 2009). The greater concentration of methionine in the MET calves during the first week of age could have been related to greater maternal transfer, which suggests a greater supply of methylation precursors during the early neonatal stage (McBreairty and Bertolo, 2016). Although we did not measure rates of protein synthesis in the present study, the temporal increases in concentration of leucine and other branched-chain AA (isoleucine, valine) in both groups of calves could be taken as an indication of enhanced availability for tissue protein synthesis (Norton and Layman, 2006; Pasiakos and McClung, 2011), particularly during the first $42 \mathrm{~d}$ of age, when there was a marked decrease in skeletal muscle protein breakdown as indicated by concentrations of 3-methylhistidine.

The fact that supply of glucose via placenta and colostrum ceases after birth means that the neonate must meet its glucose needs from lactose intake and gluconeogenesis (Mellor and Cockburn, 1986; Girard et al., 1992). Due to the lack of a functional rumen, AA in newborn preruminants are important substrates for gluconeogenesis (Girard et al., 1992; Hammon et al., 2012). In this regard, the tendency for an increase in concentration of glutamate and phenylalanine from $\mathrm{d}$ 0 to $\mathrm{d} 7$ of age in the MET calves would be expected to play a role in glucose production in the first days of age.

As part of its role in sensing insulin levels (Suryawan et al., 2009), in adult liver, MTOR induces glycolysis and inhibits gluconeogenesis through activation of AKT (Hagiwara et al., 2002). The PI3K-AKT pathway can activate glycolysis and inhibit gluconeogenesis, and the inhibition of gluconeogenesis by AKT occurs by inhibiting FOXO1 through phosphorylation (Puigserver et al., 2003). Although there was a marked decrease in p-AKT during the first $50 \mathrm{~d}$ of age, we failed to detect an upregulation of FOXO1 gene expression. Whether phosphorylation status of FOXO1 was affected merits further study. However, the gradual increase in expression of the gluconeogenic genes $P C K 1$ and $G 6 P C$ with age in both groups seems to be in line with the marked decrease in p-AKT and modest decrease in plasma insulin.

The sustained increase in expression of PCK1 and $G 6 P C$ over time reflects a gradual maturation of rumen function and provision of propionate as the main gluconeogenic substrate (Hammon et al., 2012). The gradual decrease in $P C$ expression agrees with lactate as being a more important gluconeogenic substrate soon after birth (Hammon et al., 2012) when the rumen is not fully developed. However, the overall lower expression of $P C$ in MET calves might have resulted from hypermethylation of its promoter (Pauwels et al., 2017), 
- CON

O MET

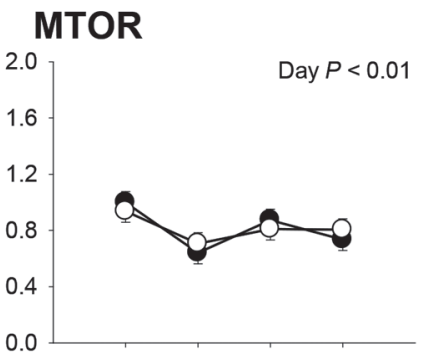

RPS6KB1

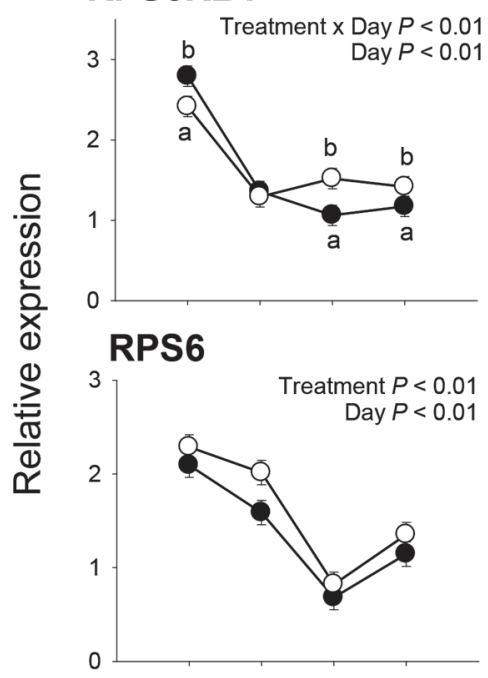

EIF4EBP1

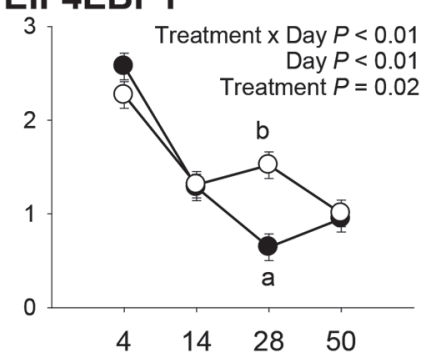

p-MTOR

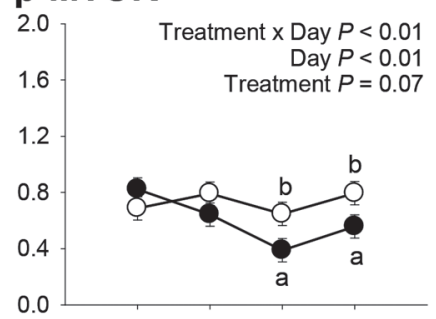

p-RPS6KB1

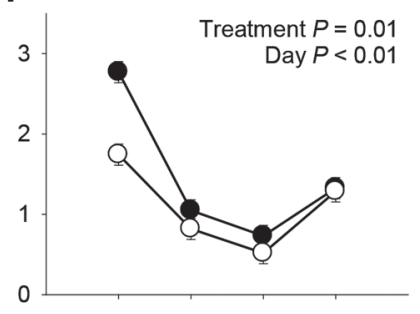

p-RPS6

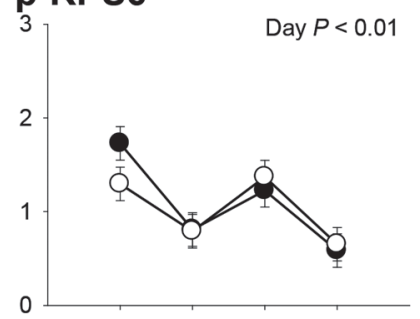

EIF4EBP1

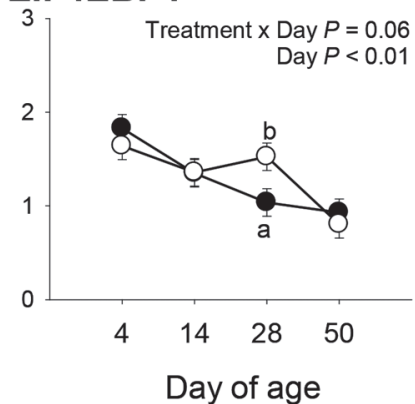

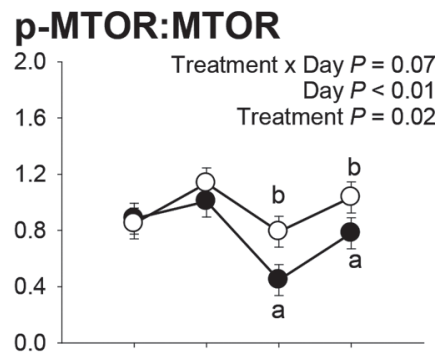

p-RPS6KB1:RPS6KB1

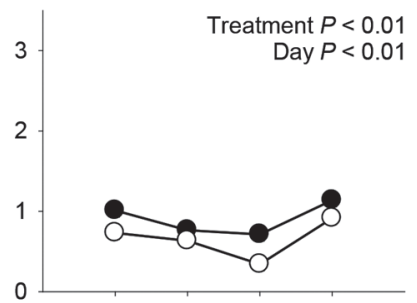

\section{p-RPS6:RPS6}

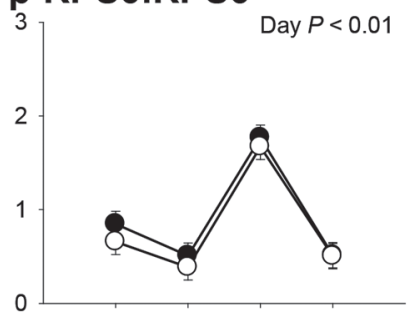

p-EIF4EBP1:EIF4EBP1

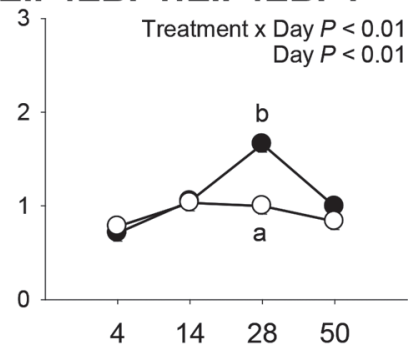

Figure 5. Abundance of total mammalian target of rapamycin (MTOR) protein, phosphorylated (p) MTOR, and ratio of p-MTOR to total MTOR; total ribosomal protein S6 kinase B1 (RPS6KB1) protein, p-RPS6KB1, and ratio of p-RPS6KB1 to total RPS6KB1; total ribosomal protein S6 (RPS6) protein, p-RPS6, and ratio of p-RPS6 to total RPS6; and total eukaryotic translation initiation factor 4E binding protein 1 (EIF4EBP1) protein, p-EIF4EBP1, and ratio of p-EIF4EBP1 to total EIF4EBP1 in liver of calves from cows fed a basal control diet (CON) or the basal diet plus ethylcellulose rumen-protected methionine (MET; 0.09\% of DMI; Mepron, Evonik Nutrition \& Care GmbH, Hanau Wolfgang, Germany) during the last $28 \mathrm{~d}$ of pregnancy. All calves were fed first-milking colostrum from their respective dams within $6 \mathrm{~h}$ postbirth. All calves received the same milk replacer until weaning at $42 \mathrm{~d}$ of age. Values are means \pm SEM. Total MTOR: maternal treatment $P=0.96$, maternal treatment $\times$ time $P=0.70$. Total RPS6KB1 protein: maternal treatment $P=0.54$. Phosphorylated RPS6KB1: maternal treatment $\times$ time $P=0.36$. Ratio of p-RPS6KB1 to total RPS6KB1: maternal treatment $\times$ time $P=0.54$. Phosphorylated 4EBP1: maternal treatment $P=$ 0.14. Ratio of p-4EBP1 to total 4EBP1: maternal treatment $P=0.66$. Means with different letters $(\mathrm{a}, \mathrm{b})$ differ $(P<0.05)$.

whereas posttranscriptional modifications clearly would contribute to differences in the expression of proteins. For instance, maternal supply of betaine (a methyl donor) during pregnancy altered methylation status of gluconeogenic genes in the liver of neonatal piglets and led to an inverse association between gene expression 
and protein expression without changing enzyme activity (Cai et al., 2014b). Therefore, a lower expression of $P C$ and $P C K 1$ may not necessarily reflect lower activity of gluconeogenic enzymes in the MET calves.

Besides exerting control on gluconeogenesis and lipogenesis, AKT plays critical roles in cell growth, survival, and protein synthesis through the phosphorylation of several effectors. The AKT isoforms (AKT1/2/3) act as necessary effectors with respect to fetal and postnatal organismal growth and further persistence of development during adulthood (Cho et al., 2001; Dummler et al., 2006). Therefore, the greater (but transient) level of phosphorylated AKT in MET calves soon after birth is suggestive of greater hepatic insulin sensitivity without detrimental effects on the ability of the calf liver to develop the gluconeogenic program. Previously, a similar response was surmised through evaluation of lipid-related genes in calves born to cows receiving an increased supply of methionine during late pregnancy (Jacometo et al., 2016). Whether this response observed in the liver also occurred in other tissues or cells of the calf remains to be determined.

In nonruminants, hepatic insulin signaling is an integral component of the lipogenic response during the fed and fasted cycles. In fact, activation of the PI3AKT pathway by insulin enhances lipogenesis through the upregulation of $S R E B F 1$ and several target genes of which $F A S N$ is a central component (Yecies et al., 2011). The gradual decrease in phosphorylation status of AKT over time is a novel finding. This response provides additional mechanistic evidence that insulin sensitivity decreases markedly during the first $3 \mathrm{mo}$ of life in calves (Pantophlet et al., 2016). An age-related decrease in insulin sensitivity has also been observed in various studies with young ruminants and nonruminants (Gelardi et al., 1999; Bergeron et al., 2007; Bach et al., 2013; Yunta et al., 2015). Therefore, as one key insulin sensor, a sustained decrease in phosphorylated $\mathrm{AKT}$ is a mechanistic adaptation of the neonatal calf as rumen function develops and the need for gluco-

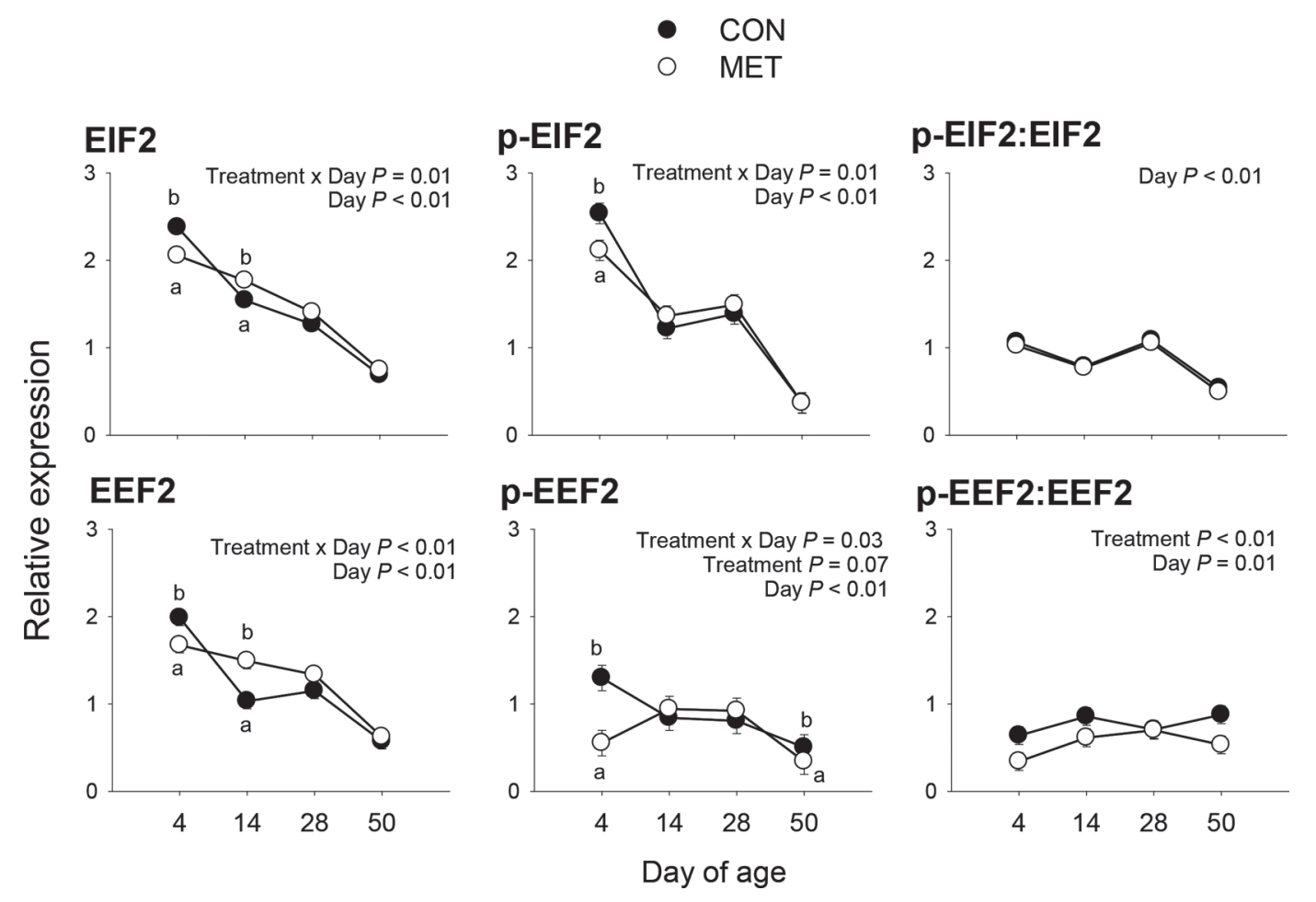

Figure 6. Abundance of total eukaryotic translation initiation factor 2 (EIF2) protein, phosphorylated (p) EIF2, and ratio of p-EIF2 to total EIF2 protein; and total translation elongation factor 2 (EEF2), p-EEF2, and ratio of p-EEF2 to total EEF2 in liver of calves born to cows fed a basal control diet (CON) or the basal diet plus ethylcellulose rumen-protected methionine (MET; 0.09\% of DMI; Mepron, Evonik Nutrition \& Care GmbH, Hanau Wolfgang, Germany) during the last 28 d of pregnancy. All calves were fed first-milking colostrum from their respective dams within $6 \mathrm{~h}$ postbirth. All calves received the same milk replacer until weaning at $42 \mathrm{~d}$ of age. Values are means \pm SEM. Total EIF2 protein: maternal treatment $P=0.20$. Phosphorylated EIF2: maternal treatment $P=0.93$. Ratio of p-EIF2 to total EIF2 protein: maternal treatment $P=0.46$, maternal treatment $\times$ time $P=0.80$. Total EEF2 protein: maternal treatment $P=0.12$. Ratio of p-EEF2 to total EEF2 protein: maternal treatment $\times$ time $P=0.32$. Means with different letters $(\mathrm{a}, \mathrm{b})$ differ $(P<0.05)$. 
neogenesis from propionate becomes more important. Furthermore, such response might have been associated with the modest change in expression of FASN and SREBF1. In the context of lipogenic regulation, however, it is noteworthy that MTOR signaling can activate lipogenesis without involvement of the PI3-AKT pathway (Laplante and Sabatini, 2010). Therefore, we speculate that the gradual increase (albeit small in nature) in lipogenic gene expression (FASN, SREBF1) with age was partly controlled via MTOR signaling.

Phosphorylation of AKT in response to an increase in the supply of AA activates MTOR (Tato et al., 2011); therefore, AKT could participate in the regulation of cell growth, protein synthesis, and gene expression (Wullschleger et al., 2006; Laplante and Sabatini, 2012). Once MTOR is activated, downstream proteins are phosphorylated and promote numerous metabolic responses involving glucose, AA, and fatty acids (Chakrabarti et al., 2010). For instance, MTOR regulates the expression of genes associated with intermediary metabolism and proteasome biogenesis in the liver of mice and cultured fetal hepatocytes (Lamming et al., 2014). Maternal dietary manipulation in nonruminants alters MTOR signaling and can affect liver development during the neonatal developmental period (Jahan-Mihan et al., 2015; Lee et al., 2016). These studies suggest that MTOR signaling is important in the regulation of neonatal liver development and metabolism.

A mechanistic link between methionine and MTOR activation in muscle cells was recently revealed, where exogenous methionine induced a quick increase in intracellular $\mathrm{Ca}^{2+}$ followed by phosphorylation of MTOR, RPS6KB1, and greater protein synthesis (Zhou et al., 2016). A role for intracellular $\mathrm{Ca}^{2+}$ in the activation of RPS6KB1 and MTOR was demonstrated more than 10 yr ago (Hannan et al., 2003). We speculate that the greater level of phosphorylated MTOR in liver of MET calves is indicative of a greater degree of nutrient utilization (e.g., AA). That idea is supported by the greater phosphorylation of AKT and lower p-EIF2 and p-EEF2 on $\mathrm{d} 4$ of age in addition to the greater concentrations of methionine, phenylalanine, threonine, glutamate, and arginine in MET calves during the first $7 \mathrm{~d}$ of age.

Among key features of MTOR signaling is the activation of RPS6KB1 and EIF4EBP1, which constitute a well-known mechanism for controlling protein synthesis and initiation of mRNA translation (Laplante and Sabatini, 2009). Therefore, the lower phosphorylation of RPS6KB1 in MET calves despite greater MTOR is not intuitive. Although rates of hepatic protein synthesis were not measured, the numerically greater concentrations of the liver-specific proteins albumin and cerulo- plasmin in MET calves offer support to the idea that protein synthesis was enhanced in those animals. At least in vitro, it is well established that AA availability in perfused liver or hepatocyte cultures influences protein turnover and albumin synthesis (Flaim et al., 1982; Hutson et al., 1987).

Although the downstream RPS6 protein phosphorylated by RPS6KB1 is generally considered to promote gene transcription and enhance ribosome biogenesis, the present study did not reveal a maternal effect of MET on RPS6 phosphorylation - an effect that could have been related to the lower overall activation of RPS6KB1. As evidenced in studies with $\mathrm{RPS}^{\mathrm{P}-/-}$ mice, the lack of effect could be partly explained by the dispensable role of RPS6 phosphorylation in global protein synthesis (Ruvinsky et al., 2005; Salmond et al., 2015). Hence, in terms of growth and development postnatally, activation of MTOR in the present study could be taken as the effector of increased maternal supply of methionine.

It is noteworthy that maternal supply of methionine also affected the phosphorylation of EEF2, another MTOR downstream target protein that catalyzes the translocation of peptidyl-tRNA from the A site to the $\mathrm{P}$ site of the ribosome (Taha et al., 2013). Phosphorylation of Thr56 by EEF2K inhibits the activity of EEF2 during protein synthesis, but MTOR phosphorylation can inhibit EEF2K activity not only through RPS6KB1 (Redpath et al., 1996; Crowell et al., 2016). For instance, Ser78 and Ser359 on EEF2K are regarded as potential phosphorylation sites regulated by MTOR without involving p-RPS6KB1 (Browne and Proud, 2002, 2004). Therefore, a lower overall degree of p-EEF2 in MET calves could be taken as further indication of activation of MTOR signaling. As such, more activated EEF2 would further facilitate general mRNA translation elongation in the liver.

A previous study revealed that AA supplementation to neonatal pigs did not alter EEF2 phosphorylation in skeletal muscle but decreased it in liver; that response was associated with greater MTOR phosphorylation (Suryawan et al., 2008). In mouse liver, protein synthesis was increased via the MTOR/EEF2 pathway in response to leucine supplementation, but no such effect was detected in skeletal muscle (Funabiki et al., 1992). Overall, these findings reveal higher sensitivity of EEF2 in liver than muscle in response to activation of MTOR signaling. Therefore, in the present study, we speculate that EEF2 was an effector of MTOR signaling and could have enhanced hepatic mRNA translation.

Collectively, the changes detected in phosphorylation of AKT, MTOR, RPS6KB1, RPS6, EIF4EBP1, and EEF2 offer support for the existence of a maternal ef- 
fect induced by the greater methionine supply during the last month of pregnancy. Whether the differences in AA profiles detected are mechanistically related to activation of the AKT/MTOR/EEF2 axis in the liver of the calves remains to be determined. Because recent evidence indicates that MTOR signaling activation by individual AA includes "priming" and "activation" (Dyachok et al., 2016), further studies will be required to isolate those steps in bovines. For example, besides the well-known role for leucine as an activating AA, in vitro data indicate that methionine, isoleucine, and valine also have that capacity (Dyachok et al., 2016). The molecular changes in the liver could result in meaningful alterations in hepatic function and likely play a role in helping calves achieve better rates of growth during the preweaning period. Additional research to clarify the underlying mechanisms for differences in phosphorylation status of MTOR pathway-related proteins as a result of increased maternal methionine supply appears warranted.

\section{ACKNOWLEDGMENTS}

Tianle $\mathrm{Xu}$ is the recipient of a scholarship from China Scholarship Council (Beijing, China). Abdulrahman S. M. Alharthi is the recipient of an MS and PhD fellowship from King Saud University (Riyadh, Saudi Arabia). Fernanda Batistel is the recipient of a fellowship from Coordenação de Aperfeiçoamento de Pessoal de Nível Superior (Brazilian Ministry of Education, Brasília, Brazil) and is supported by Hatch funds under project ILLU-538-914, National Institute of Food and Agriculture (Washington, DC).

\section{REFERENCES}

Alharthi, A. S., F. Batistel, C. Parys, A. Helmbrecht, and J. J. Loor. 2017. Maternal ethyl-cellulose rumen-protected methionine supplementation affects Holstein heifer calf development and growth. J. Dairy Sci. 100(Suppl. 2):90. (Abstr.)

Bach, A., L. Domingo, C. Montoro, and M. Terre. 2013. Short communication: Insulin responsiveness is affected by the level of milk replacer offered to young calves. J. Dairy Sci. 96:4634-4637.

Batistel, F., A. S. Alharthi, L. Wang, C. Parys, Y. X. Pan, F. C. Cardoso, and J. J. Loor. 2017a. Placentome nutrient transporters and mammalian target of rapamycin signaling proteins are altered by the methionine supply during late gestation in dairy cows and are associated with newborn birth weight. J. Nutr. 147:1640-1647.

Batistel, F., J. M. Arroyo, A. Bellingeri, L. Wang, B. Saremi, C. Parys, E. Trevisi, F. C. Cardoso, and J. J. Loor. 2017b. Ethyl-cellulose rumen-protected methionine enhances performance during the periparturient period and early lactation in Holstein dairy cows. J. Dairy Sci. 100:7455-7467.

Bauchart-Thevret, C., B. Stoll, S. Chacko, and D. G. Burrin. 2009. Sulfur amino acid deficiency upregulates intestinal methionine cycle activity and suppresses epithelial growth in neonatal pigs. Am. J. Physiol. Endocrinol. Metab. 296:E1239-E1250.

Bergeron, K., P. Julien, T. A. Davis, A. Myre, and M. C. Thivierge. 2007. Long-chain n-3 fatty acids enhance neonatal insulin-regulat- ed protein metabolism in piglets by differentially altering muscle lipid composition. J. Lipid Res. 48:2396-2410.

Browne, G. J., and C. G. Proud. 2002. Regulation of peptide-chain elongation in mammalian cells. Eur. J. Biochem. 269:5360-5368.

Browne, G. J., and C. G. Proud. 2004. A novel mTOR-regulated phosphorylation site in elongation factor 2 kinase modulates the activity of the kinase and its binding to calmodulin. Mol. Cell. Biol. 24:2986-2997.

Cai, D., Y. Jia, J. Lu, M. Yuan, S. Sui, H. Song, and R. Zhao. 2014a. Maternal dietary betaine supplementation modifies hepatic expression of cholesterol metabolic genes via epigenetic mechanisms in newborn piglets. Br. J. Nutr. 112:1459-1468.

Cai, D., Y. Jia, H. Song, S. Sui, J. Lu, Z. Jiang, and R. Zhao. 2014b. Betaine supplementation in maternal diet modulates the epigenetic regulation of hepatic gluconeogenic genes in neonatal piglets. PLoS One 9:e105504.

Cai, D., M. Yuan, H. Liu, S. Pan, W. Ma, J. Hong, and R. Zhao. 2016. Maternal betaine supplementation throughout gestation and lactation modifies hepatic cholesterol metabolic genes in weaning piglets via AMPK/LXR-mediated pathway and histone modification. Nutrients 8:E646

Chakrabarti, P., T. English, J. Shi, C. M. Smas, and K. V. Kandror 2010. Mammalian target of rapamycin complex 1 suppresses lipolysis, stimulates lipogenesis, and promotes fat storage. Diabetes $59: 775-781$

Cho, H., J. L. Thorvaldsen, Q. Chu, F. Feng, and M. J. Birnbaum. 2001. Akt1/PKB $\alpha$ is required for normal growth but dispensable for maintenance of glucose homeostasis in mice. J. Biol. Chem. $276: 38349-38352$.

Crowell, K. T., J. L. Steiner, C. S. Coleman, and C. H. Lang. 2016. Decreased whole-body fat mass produced by chronic alcohol consumption is associated with activation of S6K1-mediated protein synthesis and increased autophagy in epididymal white adipose tissue. Alcohol. Clin. Exp. Res. 40:1832-1845.

AOAC International. 1995. Official Methods of Analysis. 17th ed. Association of Official Analytical Chemists, Arlington, VA.

Du, M., M. J. Zhu, W. J. Means, B. W. Hess, and S. P. Ford. 2005. Nutrient restriction differentially modulates the mammalian target of rapamycin signaling and the ubiquitin-proteasome system in skeletal muscle of cows and their fetuses. J. Anim. Sci. 83:117-123.

Dummler, B., O. Tschopp, D. Hynx, Z. Z. Yang, S. Dirnhofer, and B. A. Hemmings. 2006. Life with a single isoform of Akt: Mice lacking Akt2 and Akt3 are viable but display impaired glucose homeostasis and growth deficiencies. Mol. Cell. Biol. 26:8042-8051.

Dyachok, J., S. Earnest, E. N. Iturraran, M. H. Cobb, and E. M. Ross. 2016. Amino acids regulate mTORC1 by an obligate twostep mechanism. J. Biol. Chem. 291:22414-22426.

Ferrell, C. L. 1991. Maternal and fetal influences on uterine and conceptus development in the cow: I. Growth of tissues of the gravid uterus. J. Anim. Sci. 69:1945-1953.

Flaim, K. E., W. S. Liao, D. E. Peavy, J. M. Taylor, and L. S. Jefferson. 1982. The role of amino acids in the regulation of protein synthesis in perfused rat liver. II. Effects of amino acid deficiency on peptide chain initiation, polysomal aggregation, and distribution of albumin mRNA. J. Biol. Chem. 257:2939-2946.

Funabiki, R., K. Yagasaki, H. Hara, N. Nyumura, F. Yoshizawa, and K. Saito. 1992. In vivo effect of L-leucine administration on protein synthesis in mice. J. Nutr. Biochem. 3:401-407.

Funston, R. N., D. M. Larson, and K. A. Vonnahme. 2010. Effects of maternal nutrition on conceptus growth and offspring performance: Implications for beef cattle production. J. Anim. Sci. 88:E205-E215.

Gelardi, N. L., R. E. Rapoza, J. F. Renzulli, and R. M. Cowett. 1999. Insulin resistance and glucose transporter expression during the euglycemic hyperinsulinemic clamp in the lamb. Am. J. Physiol. 277:E1142-E1149.

Girard, J., P. Ferre, J. P. Pegorier, and P. H. Duee. 1992. Adaptations of glucose and fatty acid metabolism during perinatal period and suckling-weaning transition. Physiol. Rev. 72:507-562.

Hagiwara, A., M. Cornu, N. Cybulski, P. Polak, C. Betz, F. Trapani, L. Terracciano, M. H. Heim, M. A. Rüegg, and M. N. Hall. 2002. 
Hepatic mTORC2 activates glycolysis and lipogenesis through Akt, glucokinase, and SREBP1c. Cell Metab. 15:725-738.

Hammon, H. M., J. Steinhoff-Wagner, U. Schonhusen, C. C. Metges, and J. W. Blum. 2012. Energy metabolism in the newborn farm animal with emphasis on the calf: Endocrine changes and responses to milk-born and systemic hormones. Domest. Anim. Endocrinol. 43:171-185.

Hannan, K. M., G. Thomas, and R. B. Pearson. 2003. Activation of S6K1 (p70 ribosomal protein S6 kinase 1) requires an initial calcium-dependent priming event involving formation of a highmolecular-mass signalling complex. Biochem. J. 370:469-477.

Hutson, S. M., C. Stinson-Fisher, R. Shiman, and L. S. Jefferson. 1987. Regulation of albumin synthesis by hormones and amino acids in primary cultures of rat hepatocytes. Am. J. Physiol. 252:E291E298.

Jacometo, C. B., J. S. Osorio, M. Socha, M. N. Correa, F. PiccioliCappelli, E. Trevisi, and J. J. Loor. 2015. Maternal consumption of organic trace minerals alters calf systemic and neutrophil mRNA and microRNA indicators of inflammation and oxidative stress. J. Dairy Sci. 98:7717-7729.

Jacometo, C. B., Z. Zhou, D. Luchini, M. N. Correa, and J. J. Loor. 2017. Maternal supplementation with rumen-protected methionine increases prepartal plasma methionine concentration and alters hepatic mRNA abundance of 1-carbon, methionine, and transsulfuration pathways in neonatal Holstein calves. J. Dairy Sci. 100:3209-3219.

Jacometo, C. B., Z. Zhou, D. Luchini, E. Trevisi, M. N. Correa, and J. J. Loor. 2016. Maternal rumen-protected methionine supplementation and its effect on blood and liver biomarkers of energy metabolism, inflammation, and oxidative stress in neonatal Holstein calves. J. Dairy Sci. 99:6753-6763.

Jahan-Mihan, A., J. Rodriguez, C. Christie, M. Sadeghi, and T. Zerbe. 2015. The role of maternal dietary proteins in development of metabolic syndrome in offspring. Nutrients 7:9185-9217.

Khan, M. A., H. J. Lee, W. S. Lee, H. S. Kim, K. S. Ki, T. Y. Hur, G. H. Suh, S. J. Kang, and Y. J. Choi. 2007. Structural growth, rumen development, and metabolic and immune responses of Holstein male calves fed milk through step-down and conventional methods. J. Dairy Sci. 90:3376-3387.

Lamming, D. W., G. Demirkan, J. M. Boylan, M. M. Mihaylova, T. Peng, J. Ferreira, N. Neretti, A. Salomon, D. M. Sabatini, and P. A. Gruppuso. 2014. Hepatic signaling by the mechanistic target of rapamycin complex 2 (mTORC2). FASEB J. 28:300-315.

Lane, M. A., R. L. T. Baldwin, and B. W. Jesse. 2002. Developmental changes in ketogenic enzyme gene expression during sheep rumen development. J. Anim. Sci. 80:1538-1544.

Lansard, M., S. Panserat, E. Plagnes-Juan, K. Dias, I. Seiliez, and S. Skiba-Cassy. 2011. L-Leucine, L-methionine, and L-lysine are involved in the regulation of intermediary metabolism-related gene expression in rainbow trout hepatocytes. J. Nutr. 141:75-80.

Laplante, M., and D. M. Sabatini. 2009. mTOR signalling at a glance. J. Cell Sci. 122:3589-3594.

Laplante, M., and D. M. Sabatini. 2010. mTORC1 activates SREBP$1 \mathrm{c}$ and uncouples lipogenesis from gluconeogenesis. Proc. Natl. Acad. Sci. USA 107:3281-3282.

Laplante, M., and D. M. Sabatini. 2012. mTOR signaling in growth control and disease. Cell 149:274-293.

Lee, S., Y. A. You, E. J. Kwon, S. C. Jung, I. Jo, and Y. J. Kim. 2016 Maternal food restriction during pregnancy and lactation adversely affect hepatic growth and lipid metabolism in three-week-old rat offspring. Int. J. Mol. Sci. 17:E2115.

Loor, J. J., M. Bionaz, and J. K. Drackley. 2013. Systems physiology in dairy cattle: Nutritional genomics and beyond. Annu. Rev. Anim. Biosci. 1:365-392.

McBreairty, L. E., and R. F. Bertolo. 2016. The dynamics of methionine supply and demand during early development. Appl. Physiol. Nutr. Metab. 41:581-587.

Mellor, D. J., and F. Cockburn. 1986. A comparison of energy metabolism in the new-born infant, piglet and lamb. Q. J. Exp. Physiol. $71: 361-379$.
Naeem, A., J. K. Drackley, J. Stamey, and J. J. Loor. 2012. Role of metabolic and cellular proliferation genes in ruminal development in response to enhanced plane of nutrition in neonatal Holstein calves. J. Dairy Sci. 95:1807-1820. https://doi.org/10.3168/jds .2011-4709.

Norton, L. E., and D. K. Layman. 2006. Leucine regulates translation initiation of protein synthesis in skeletal muscle after exercise. J. Nutr. 136:533S-537S.

Osorio, J. S., P. Ji, J. K. Drackley, D. Luchini, and J. J. Loor. 2013. Supplemental Smartamine M or MetaSmart during the transition period benefits postpartal cow performance and blood neutrophil function. J. Dairy Sci. 96:6248-6263.

Pantophlet, A. J., M. S. Gilbert, J. J. van den Borne, W. J. Gerrits, M. G. Priebe, and R. J. Vonk. 2016. Insulin sensitivity in calves decreases substantially during the first 3 months of life and is unaffected by weaning or fructo-oligosaccharide supplementation. J. Dairy Sci. 99:7602-7611.

Pasiakos, S. M., and J. P. McClung. 2011. Supplemental dietary leucine and the skeletal muscle anabolic response to essential amino acids. Nutr. Rev. 69:550-557.

Pauwels, S., M. Ghosh, R. C. Duca, B. Bekaert, K. Freson, I. Huybrechts, S. A. S. Langie, G. Koppen, R. Devlieger, and L. Godderis. 2017. Maternal intake of methyl-group donors affects DNA methylation of metabolic genes in infants. Clin. Epigenetics 9:16.

Prior, R. L., and R. K. Christenson. 1977. Gluconeogenesis from alanine in vivo by the ovine fetus and lamb. Am. J. Physiol. 233:E462-E468

Prior, R. L., and R. A. Scott. 1977. Ontogeny of gluconeogenesis in the bovine fetus: Influence of maternal dietary energy. Dev. Biol. $58: 384-393$.

Puigserver, P., J. Rhee, J. Donovan, C. J. Walkey, J. C. Yoon, F Oriente, Y. Kitamura, J. Altomonte, H. Dong, D. Accili, and B. M. Spiegelman. 2003. Insulin-regulated hepatic gluconeogenesis through FOXO1-PGC-1alpha interaction. Nature 423:550-555.

Redpath, N. T., E. J. Foulstone, and C. G. Proud. 1996. Regulation of translation elongation factor-2 by insulin via a rapamycin-sensitive signalling pathway. EMBO J. 15:2291-2297.

Ruvinsky, I., N. Sharon, T. Lerer, H. Cohen, M. Stolovich-Rain, T. Nir, Y. Dor, P. Zisman, and O. Meyuhas. 2005. Ribosomal protein S6 phosphorylation is a determinant of cell size and glucose homeostasis. Genes Dev. 19:2199-2211.

Salmond, R. J., R. J. Brownlie, O. Meyuhas, and R. Zamoyska. 2015. Mechanistic target of rapamycin complex 1/S6 kinase 1 signals influence $\mathrm{T}$ cell activation independently of ribosomal protein S6 phosphorylation. J. Immunol. 195:4615-4622.

Stevenson, R. E., F. H. Morriss Jr., E. W. Adcock 3rd, and R. R. Howell. 1976. Development of gluconeogenic enzymes in fetal sheep liver and kidney. Dev. Biol. 52:167-172.

Suryawan, A., A. S. Jeyapalan, R. A. Orellana, F. A. Wilson, H. V. Nguyen, and T. A. Davis. 2008. Leucine stimulates protein synthesis in skeletal muscle of neonatal pigs by enhancing mTORC1 activation. Am. J. Physiol. Endocrinol. Metab. 295:E868-E875.

Suryawan, A., P. M. O'Connor, J. A. Bush, H. V. Nguyen, and T. A. Davis. 2009. Differential regulation of protein synthesis by amino acids and insulin in peripheral and visceral tissues of neonatal pigs. Amino Acids 37:97-104

Taha, E., I. Gildish, S. Gal-Ben-Ari, and K. Rosenblum. 2013. The role of eEF2 pathway in learning and synaptic plasticity. Neurobiol. Learn. Mem. 105:100-106.

Tato, I., R. Bartrons, F. Ventura, and J. L. Rosa. 2011. Amino acids activate mammalian target of rapamycin complex 2 (mTORC2) via PI3K/Akt signaling. J. Biol. Chem. 286:6128-6142.

Vailati-Riboni, M., M. Kanwal, O. Bulgari, S. Meier, N. V. Priest, C. R. Burke, J. K. Kay, S. McDougall, M. D. Mitchell, C. G. Walker, M. Crookenden, A. Heiser, J. R. Roche, and J. J. Loor. 2016. Body condition score and plane of nutrition prepartum affect adipose tissue transcriptome regulators of metabolism and inflammation in grazing dairy cows during the transition period. J. Dairy Sci. 99:758-770. 
Wu, G. 2013. Amino Acids: Biochemistry and Nutrition. CRC Press, Boca Raton, FL.

Wullschleger, S., R. Loewith, and M. N. Hall. 2006. TOR signaling in growth and metabolism. Cell 124:471-484.

Yao, K., Y. L. Yin, W. Chu, Z. Liu, D. Deng, T. Li, R. Huang, J. Zhang, B. Tan, W. Wang, and G. Wu. 2008. Dietary arginine supplementation increases mTOR signaling activity in skeletal muscle of neonatal pigs. J. Nutr. 138:867-872.

Yecies, J. L., H. H. Zhang, S. Menon, S. Liu, D. Yecies, A. I. Lipovsky, C. Gorgun, D. J. Kwiatkowski, G. S. Hotamisligil, C. H. Lee, and B. D. Manning. 2011. Akt stimulates hepatic SREBP1c and lipogenesis through parallel mTORC1-dependent and independent pathways. Cell Metab. 14:21-32.

Yunta, C., M. Terré, and A. Bach. 2015. Short- and medium-term changes in performance and metabolism of dairy calves offered different amounts of milk replacers. Livest. Sci. 181:249-255.
Zhou, Y., J. Ren, T. Song, J. Peng, and H. Wei. 2016. Methionine regulates mTORC1 via the T1R1/T1R3-PLC-Ca2+-ERK1/2 signal transduction process in C2C12 cells. Int. J. Mol. Sci. 17:1684.

Zhou, Z., M. Vailati-Riboni, D. N. Luchini, and J. J. Loor. 2016a. Methionine and choline supply during the periparturient period alter plasma amino acid and one-carbon metabolism profiles to various extents: Potential role in hepatic metabolism and antioxidant status. Nutrients 9:E10.

Zhou, Z., M. Vailati-Riboni, E. Trevisi, J. K. Drackley, D. N. Luchini, and J. J. Loor. 2016b. Better postpartal performance in dairy cows supplemented with rumen-protected methionine compared with choline during the peripartal period. J. Dairy Sci. 99:8716-8732. 